\title{
Structure, development and evolution of the digestive system
}

\author{
V. Hartenstein ${ }^{1}$ P. Martinez $z^{2,3}$
}

Published online: 2 September 2019

(C) Springer-Verlag GmbH Germany, part of Springer Nature 2019

\section{Summary}

Living cells depend on a constant supply of energy-rich organic molecules from the environment. Small molecules pass into the interior of the cell via simple diffusion or active transport carried out by membrane bound transporters; macromolecules, or entire cells, are taken up by endocytosis/phagocytosis, and are degraded intracellularly in specialized membrane bound compartments (lysosomes). Whereas all cells are capable of transporting molecules through the membrane, the efficient procurement, digestion and uptake of nutrients have become the function of specialized cell types and organs, forming the digestive system in multicellular animals. In mammals, for example, the digestive system is comprised of glandular organs with classes of cells specialized in the secretion of enzymes for the extracellular digestion of food particles (e.g., exocrine cells of the salivary gland, pancreas), as well as other organs with absorptive function (e.g., small intestine). Numerous other cell types, such as smooth muscle cells, neurons and enteroendocrine cells, are associated with glandular cells and intestinal cells to promote the digestive process.

The complex mammalian digestive system is a highly derived character among animals. It is well known that animals belonging to more early diversified clades, such as Porifera or Cnidaria, ingest food mainly in the form of

V. Hartenstein

volkerh@mcdb.ucla.edu

P. Martinez

Pedro.martinez@ub.edu

1 Department of Molecular, Cell and Developmental Biology, University of California, Los Angeles (UCLA), Los Angeles, CA, USA

2 Departament de Genètica, Microbiologia i Estadística, Universitat de Barcelona, Av. Diagonal 643, 08028 Barcelona, Spain

3 ICREA (Institut Català de Recerca i Estudis Avancats), Passeig Lluís Companys 23, 08010 Barcelona, Spain single cells (e.g., bacteria, microalgae, protists) that are taken up phagocytotically and degraded subsequently by intracellular digestion (Lunger 1963; Afzelius and Rosén 1965; Weissenfels 1976; Imsiecke 1993). Historically, the widespread occurrence of phagocytosis and intracellular digestion among invertebrates was clearly recognized by pioneers of cell biology, such as Metschnikoff (1884). More recently, the push to analyze physiological processes, like digestion, at a cellular and molecular level has restricted our focus towards a few experimentally tractable model systems, which include vertebrates, as well as a few invertebrates (the insect Drosophila melanogaster or the nematode Caenorhabditis elegans, where food assimilation also occurs mainly by extracellular digestion (see Holtof et al. 2019; Dimov and Maduro 2019, this issue). As a result, the pervasive role of phagocytosis and intracellular digestion in animal digestion has remained less investigated, and this includes both the cellular organization and the essential molecular players. For most phyla the mechanisms controlling digestion are scarcely known, leaving us with a very fragmentary view of the evolution of digestive systems. With new technologies having been made available in recent years, and phylogenetic relationships between different taxa becoming clearer, it is now possible to address cellular and molecular details of food digestion and uptake in the context of evolution. For the first time we are able to follow the evolution of cell types, specification genes and digestive system's architectures in many animal groups. OMIC approaches, including singe cell molecular profiles are telling us some of the evolutionary paths that digestion and its constitutive components have followed over evolutionary time. The present special issue of Cell and Tissue Research presents a series of reviews that look at the current state of knowledge in this area, addressing some of the relevant issues concerning (1) regionalization and development of the gut; (2) the role of extracellular digestion and phagocytosis in food assimilation; (3) structure, development and evolution of the gut endocrine 
system; (4) functional and evolutionary relationship between the digestive and immune system.

\section{Conserved genetic mechanism specify diverse guts}

In all animals excepting the basal clade of Placozoa, digestion is the function of epithelial cells lining an inner lumen (gut cavity). The general pattern of the gut and the way to regionalize it seem to depend on many shared genes, which points to the fact that the general organization of the gut is, most probably, evolutionarily ancient, dating back to the cnidarianbilaterian (the "old" Planulozoa) ancestor. Molecular-genetic studies have revealed important themes in gut development, and several reviews of the special issue summarize the current knowledge in this area [Annunziata et al. 2019, for echinoderms; Nakayama et al. 2019, for protochordates; Dimov and Maduro 2019 for nematodes; Steinmetz 2019 for cnidarians]. Contrasting with a strongly conserved repertoire of genetic mechanisms acting in gut development is the evident diversity of the architectures and cellular compositions of the digestive systems, which results from the need to adapt to the different types of food that animals consume. Examples of gut diversity surveyed in detail in this special issue include the sponges (Godefroy et al. 2019), acoels (Gavilán et al. 2019) and molluscs (Lobo-da-Cunha 2019).

\section{Cellular mechanisms of extracellular and intracellular digestion}

When considering the evolutionary origins of the digestive system, the ventral epithelial cells of Placozoa that phagocytose microorganisms trapped in the cleft between the animal and the substrate, may present an anatomical scenario from which more complex digestive systems evolved (Smith and Mayorova 2019, this issue). In all other animals phagocytotic cells carrying out the digestive process are associated with internal chambers. In sponges, these cells are represented by choanocytes, which, together with mesenchymal archaeocytes, are responsible for the uptake, intracellular digestion, and distribution of nutrients (Imsiecke 1993; Godefroy et al. 2019, this issue). In ctenophores, cnidarians and bilaterians, phagocytes form a gastrodermal (or intestinal) epithelium, which also contains other cell types, notably secretory (glandular) cells and endocrine cells (Chapman 1978; Van-Praët 1985; Steinmetz 2019, this issue; Hartenstein and Martinez 2019, this issue). Enzymes produced by secretory cells break down nutrients, and in some clades (e.g., vertebrates, most insects) extracellular digestion followed by absorption of small molecules have superseded phagocytosis and intracellular digestion as the main mechanism of food assimilation (Holtof et al. 2019, this issue). However, in most clades, including protochordates, which are the closest relatives of vertebrates, phagocytosis combined with intracellular digestion is the predominant method of operation of the digestive system (He et al. 2018; Nakayama et al. 2019, this issue; Satake et al. 2019, this issue). Cellular and molecular details of these processes are not known in detail. Studies that do exist mainly include descriptions of the ultrastructure of cells involved in digestion, and these are reviewed in this special issue for several specific clades by Smith and Mayorova (2019; Placozoa), Godefroy et al. (2019; Porifera), Gavilán et al. (2019; Xenacoelomorpha), Lobo-da-Cunha (2019; Mollusca), Štrus et al. (2019; Crustacea) and Caccia et al. (2019; Hexapoda) and for prebilaterian and bilaterian clades in more general, by Steinmetz (2019) and Hartenstein and Martinez (2019), respectively.

\section{The gut endocrine system}

An interesting issue raised by some recent studies is the control of digestive functions by different neuropeptides. The recent flurry of papers dealing with the sequencing of animal genomes has provided us with detailed catalogues of putative neuropeptides in many clades, some of which might be involved in the control of intestinal functions. This is the case of some echinoderms (García-Arrarás et al. 2019, this issue) that express neuropeptides in the enteroendocrine cells. Whether these cells contact/respond to the nervous system is a matter of current investigation. In other chordate systems, such as the lancelet Branchiostoma floridae, neuropeptides seem to be also expressed in the alimentary canal (Nakayama et al. 2019, this issue). Moreover in the urochordate model Ciona intestinalis (described by Satake et al. 2019) many peptides/receptors have been detected in the alimentary canal (including some clade-specific peptides). Annunziata et al. (2019, this issue) report the presence of insulin-like producing cells located in a particular domain of the gut in what they assume to be endocrine cells.

Other authors that mention the presence of specific neuropeptides in the gut, without going into details, are Štrus et al. 2019; Holtof et al. 2019 and Caccia et al. 2019; all three dealing with the Arthropoda and, for the old placozoan lineage, which shares neuropeptides with other bilaterian clades, Smith and Mayorova (2019). Poriferans do not seem to have secretory peptides in their genomes and the ctenophores use a completely different set of peptides unrelated to those of any other metazoan phyla (Moroz et al. 2014). Though the capacity to generate peptides seems to be a premetazoan invention, the use for regulation of digestive roles seems to be associated to the emergence of the Planulozoa (Bilateria + Cnidaria; depending of the phylogenetic position accepted for the Placozoa). 


\section{Immunity and digestion: functional and evolutionary relationships}

Our current knowledge of phagocytosis and lysosomal digestion is mainly informed by studies on macrophages, motile phagocytic cells that ingest invading microorganisms and cellular debris resulting from tissue damage. Macrophages also play important developmental roles, removing apoptotic cells and laying down extracellular matrices. Little is known about the relationship between the the immune system and digestive system. Functionally, both systems have to cooperate, given the immunological challenge caused by the ingestion of particles directly from the environment (a clear case are aquatic animals). In the reviews provided by Buckley and Rast (2019, this issue), Nakayama et al. (2019, this issue) and Satake et al. (2019, this issue) a detailed analysis of the molecular players involved in the interaction of the immune system and the gut epithelia in larval echinoderms and protochordates is presented. Interestingly, some players are shared between this system and vertebrates (i.e. IL-17), which point to some common (ancient) systems of interaction between immune cells and those of the gut epithelium, recognizing the gut as the physical location of interaction between the immune system and the microbiota (beneficial or pathogenic) of the gut lumen".

In regard to ultrastructure, macrophages of the immune system and phagocytes of the digestive system of most invertebrates have many features in common (Hartenstein and Martinez 2019, this issue), prompting the question of common roots unifying these two cell types. Developmentally, they derive from two different germ layers, the mesoderm and endoderm, respectively. However, it is possible that at the root of the metazoan tree, they formed a common pool of cells. This can still be seen in extant sponges, where phagocytes lining the choanocyte chambers (choanocytes, "enteric phagocytes") can convert into motile archaeocytes ("macrophages") that inhabit the interior space (mesohyl), and vice versa (Nakanishi et al. 2014; Sogabe et al. 2016). For some bilateran clades, in particular annelids (Kermack 1955) and echinoderms (Chia and Koss 1991), motile macrophages (coelomocytes) also become associated with the intestinal epithelium, where they could be involved in immune functions, as well as food uptake. An intriguing evolutionary scenario, based on recent studies in cnidarians, is proposed by Steinmetz (2019; this issue), according to which the phagocytes and other cell types of the endoderm of the cnidarianbilateran ancestor gave rise to the bilaterian mesoderm; the bilaterian endoderm and its products, including gland cells and endocrine cells, evolved from the ectoderm of the cnidarian-bilateran ancestor. This sequence of events would explain how endodermal phagocytes, initially involved in food uptake in the cnidarian-bilateran ancestor, evolved into macrophages in the bilaterian lineage. On the other hand, one would have to assume that other cell types commonly found in the bilaterian intestinal epithelium, including phagocytes, evolved convergently, which (given the widespread distribution of these cells among different bilaterian clades) appears unlikely. However, one should note that, despite shared structural and functional characters, homology between any of these cell types (e.g., archaeocytes in sponges; enteric phagocytes in cnidarians and various bilaterian taxa) has not been established. Fortunately, currently available tools make it possible to gain detailed insight into the genetic makeup of cells, and we can be hopeful that in the near future we will have a clearer picture of the evolutionary relationship between phagocytes and other cell types of the gut, as well as macrophages carrying out immune functions.

\section{References}

Afzelius BA, Rosén B (1965) Nutritive phagocytosis in animal cells. An electron microscopical study of the gastroderm of the hydroid Clava squamata Müll. Z Zellforsch Mikrosk Anat 67:24-33

Annunziata R, Andrikou C, Perillo M, Cuomo C, Arnone MI (2019) Development and evolution of gut structures: from molecules to function. Cell Tissue Res https://doi.org/10.1007/s00441-01903093-9

Buckley KM, Rast JP (2019) Immune activity at the gut epithelium in the larval sea urchin. Cell Tissue Res https://doi.org/10.1007/s00441019-03095-7

Caccia, S, Casartelli, M, and Tettamanti, G (2019) The amazing complexity of insect midgut cells: types, peculiarities, and functions. Cell Tissue Res https://doi.org/10.1007/s00441-019-03076-w

Chapman DM (1978) Microanatomy of the cubopolyp,Tripedalia cystophora (class Cubozoa). Helgoländer Meeresun 31:128-168. https://doi.org/10.1007/BF02296994

Chia FS, Koss R (1991) Asteroidea. In: Harrison FW, Chia TS (eds) Microscopic anatomy of invertebrates, vol 14. John Wiley and Sons, New York, pp 169-246

Dimov I, Maduro MF (2019) The C. elegans intestine: organogenesis, digestion, and physiology. Cell Tissue Res https://doi.org/10.1007/ s00441-019-03036-4

García-Arrarás JE, Lefebre-Rivera M, Qi-Huang S (2019) Enteroendocrine cells in the Echinodermata. Cell Tissue Res https://doi.org/10.1007/s00441-019-03053-3

Gavilán B, Sprecher SG, Hartenstein V, Martinez P (2019) The digestive system of xenacoelomorphs. Cell Tissue Res https://doi.org/10. 1007/s00441-019-03038-2

Godefroy N, Le Goff E, Martinand-Mari C, Belkhir K, Vacelet J, Baghdiguian S (2019) Sponge digestive system diversity and evolution: filter feeding to carnivory. Cell Tissue Res https://doi.org/10. 1007/s00441-019-03032-8

Hartenstein V, Martinez P (2019) Phagocytosis in cellular defense and nutrition: a food-centered approach to the evolution of macrophages. Cell Tissue Res https://doi.org/10.1007/s00441-019-03096-6

He C, Han T, Liao X, Zhou Y, Wang X, Guan R, Tian T, Li Y, Bi C, Lu N, He Z, Hu B, Zhou Q, Hu Y, Lu Z, Chen JY (2018) Phagocytic intracellular digestion in amphioxus (Branchiostoma). Proc Biol Sci 285:20180438. https://doi.org/10.1098/rspb.2018.0438

Holtof M, Lenaerts C, Cullen D, Van den Broeck J (2019) Extracellular nutrient digestion and absorption in the insect gut. Cell Tissue Res https://doi.org/10.1007/s00441-019-03031-9 
Imsiecke G (1993) Ingestion, digestion, and egestion in Spongilla lacustris (Porifera, Spongillidae) after pulse feeding with Chlamydomonas reinhardtii (Volvocales). Zoomorphology 113: 233-244. https://doi.org/10.1007/BF00403314

Kermack DM (1955) The anatomy and physiology of the gut of the polychaete Arenicola marina (L.). Proc Zool Soc London 125: 347-381

Lobo-da-Cunha A (2019) Structure and function of the digestive system in Molluscs. Cell Tissue Res https://doi.org/10.1007/s00441-01903085-9

Lunger PD (1963) Fine-structural aspects of digestion in a colonial hydroid. J Ultrastruct Res 9:362-380. https://doi.org/10.1016/S00225320(63)80012-X

Metschnikoff E (1884) Memoirs: researches on the intracellular digestion of invertebrates. J Cell Sci 93:89-111

Moroz LL, Kocot KM, Citarella MR, Dosung S, Norekian TP, Povolotskaya IS, Grigorenko AP, Dailey C, Berezikov E, Buckley KM, Ptitsyn A, Reshetov D, Mukherjee K, Moroz TP, Bobkova Y, Yu F, Kapitonov VV, Jurka J, Bobkov YV, Swore JJ, Girardo DO, Fodor A, Gusev F, Sanford R, Bruders R, Kittler E, Mills CE, Rast JP, Derelle R, Solovyev VV, Kondrashov FA, Swalla BJ, Sweedler JV, Rogaev EI, Halanych KM, Kohn AB (2014) The ctenophore genome and the evolutionary origins of neural systems. Nature. 510(7503):109-114. https://doi.org/10.1038/nature13400

Nakanishi N, Sogabe S, Degnan BM (2014) Evolutionary origin of gastrulation: insights from sponge development. BMC Biol 12:26. https://doi.org/10.1186/1741-7007-12-26

Nakayama S, Sekiguchi T, Ogasawara, M ( 2019) Molecular and evolutionary aspects of the protochordate digestive system. Cell Tissue Res https://doi.org/10.1007/s00441-019-03035-5
Satake H, Matsubara S, Shiraishi A, Yamamoto T, Osugi T, Sakai T, Kawada T (2019) Peptide receptors and immune-related proteins expressed in the digestive system of a urochordate, Ciona intestinalis. Cell Tissue Res https://doi.org/10.1007/s00441019-03024-8

Smith CL, Mayorova TD (2019) Insights into the evolution of digestive systems from studies of Trichoplax adhaerens. Cell Tissue Res https://doi.org/10.1007/s00441-019-03057-z

Sogabe S, Nakanishi N, Degnan BM (2016) The ontogeny of choanocyte chambers during metamorphosis in the demosponge Amphimedon queenslandica. Evodevo 7:6. https://doi.org/10. 1186/s13227-016-0042-x

Steinmetz PRH (2019) A non-bilaterian perspective on the development and evolution of animal digestive systems Cell Tissue Res https:// doi.org/10.1007/s00441-019-03075-x

Štrus J, Žnidaršič N, Mrak P, Bogataj U, Vogt, G (2019) Structure, function and development of the digestive system in malacostracan crustaceans and adaptation to different lifestyles. Cell Tissue Res https:// doi.org/10.1007/s00441-019-03056-0

Van-Praët M (1985) Nutrition of sea anemones. In: Adv Mar Biol Volume 22. Elsevier, pp 65-99

Weissenfels N (1976) Bau und Funktion des Süwasserschwamms Ephydatia fluviatilis L. (Porifera). Zoomorphologie 85:73-88. https://doi.org/10.1007/BF00995405

Publisher's note Springer Nature remains neutral with regard to jurisdictional claims in published maps and institutional affiliations. 